\title{
Fractures in myelomeningocele
}

\author{
Michael Akbar • Bjoern Bresch • Patric Raiss • \\ Carl Hans Fürstenberg • Thomas Bruckner • \\ Thorsten Seyler · Claus Carstens · Rainer Abel
}

Received: 25 January 2010/ Accepted: 22 July 2010/Published online: 19 August 2010

(C) The Author(s) 2010. This article is published with open access at Springerlink.com

\begin{abstract}
Background In patients with myelomeningocele (MMC), a high number of fractures occur in the paralyzed extremities, affecting mobility and independence. The aims of this retrospective cross-sectional study are to determine the frequency of fractures in our patient cohort and to identify trends and risk factors relevant for such fractures. Materials and methods Between March 1988 and June 2005, 862 patients with MMC were treated at our hospital. The medical records, surgery reports, and X-rays from these patients were evaluated.

Results During the study period, $11 \%$ of the patients $(n=92)$ suffered one or more fractures. Risk analysis showed that patients with MMC and thoracic-level paralysis had a sixfold higher risk of fracture compared with those with sacral-level paralysis. Femoral-neck $z$-scores
\end{abstract}

Level of evidence: level IV, case series.

Work performed at the Department of Orthopaedic Surgery, Trauma Surgery and Division of Spinal Cord Injury, University of Heidelberg, Heidelberg, Germany.

M. Akbar $(\bowtie) \cdot$ B. Bresch · P. Raiss · C. H. Fürstenberg ·

C. Carstens - R. Abel

Department of Orthopaedic Surgery, Trauma Surgery and

Division of Spinal Cord Injury, University of Heidelberg,

Schlierbacher Landstrasse 200A, 69118 Heidelberg, Germany

e-mail: michael.akbar@med.uni-heidelberg.de

T. Bruckner

Department of Medical Biometry and Informatics,

University of Heidelberg, Heidelberg, Germany

T. Seyler

Department of Orthopaedic Surgery, Wake Forest University

School of Medicine, Winston-Salem, NC, USA measured by dual-energy X-ray absorptiometry (DEXA) differed significantly according to the level of neurological impairment, with lower $z$-scores in children with a higher level of lesion. Furthermore, the rate of epiphyseal separation increased noticeably after cast immobilization. Mainly patients who could walk relatively well were affected.

Conclusions Patients with thoracic-level paralysis represent a group with high fracture risk. According to these results, fracture and epiphyseal injury in patients with MMC should be treated by plaster immobilization. The duration of immobilization should be kept to a minimum ( $<4$ weeks) because of increased risk of secondary fractures. Alternatively, patients with refractures can be treated by surgery, when nonoperative treatment has failed.

Keywords Myelomeningocele $\cdot$ Fractures $\cdot$ Risk factors · Risk analysis - Lesion level · Bone mineral density

\section{Introduction}

Neural tube anomalies develop at a rate of $2-9$ per 1,000 births in Central Europe and North America [4, 13, 20]. In 2005 the rate of myelomeningocele (MMC) was 18.0 per 100,000 births in the USA [7]. Thus, it represents the third most common birth defect after cleft lip and palate and anomalies of the extremities.

The main focus of orthopedic care in MMC is prevention and treatment of skeletal malformations of the spine and the extremities. Preservation of maximum walking ability [28] is an example of a functional goal. A major obstacle for developmental rehabilitation is the increased incidence of fractures in the paralyzed lower extremities, which restrict mobility and independence of the children 
and often necessitate long periods of hospitalization [10, 12, 14, 18, 21, 22].

Children with MMC are at increased risk of pathological fractures due to motor and sensory deficits and disuse of lower limbs compared with their able-bodied peers. It has been demonstrated that children with MMC have a bone mineral density one to two standard deviations below the mean of the normal population [32].

Fractures complicate the management of children who have MMC [1, 6, 10, 12, 13, 20, 23, 24, 27, 33, 45]. A fracture most often causes painless swelling, hyperthermia, and hyperemia in the affected limb [10, 23, 41, 42, 45]. Furthermore, fever and leukocytosis can develop and the erythrocyte sedimentation rate can increase, which delays diagnosis [1, 6, 16, 23, 24, 27, 33, 41, 42, 45].

Radiographs and often follow-up X-rays are the key to correct diagnosis, as fracture patterns are unique and different from those seen in children who are neurologically intact [16, 27, 41, 45].

In some studies the prevalence of fractures has been reported to be between $9 \%$ [31] and 20\% [5, 9, 10, 21, 23, 30, 33, 34, 45]. Epiphyseal fractures occur frequently in patients with MMC at rates of 4-9\% [8, 9, 28] and can affect further bone growth. In contrast to other kinds of fractures, epiphyseal injuries mainly seem to affect those MMC children who can walk relatively well [24, 27]. Some authors have already suggested that the level of paralysis may be an influencing factor in fracture development [9, 27, 30], but they did not analyze their data statistically due to the small number of cases. Studies have shown conflicting results in the incidence of fractures in MMC children who ambulate compared with those who use wheelchairs [26, 32, 37].

As fractures pose a considerable risk to physical development and independence, the aims of this retrospective cross-sectional study are to determine the frequency and location of fractures in our patient cohort, to identify factors that promote fractures, to correlate bone mineral density to fracture incidence, and to recommend suitable treatment options.

\section{Materials and methods}

For this retrospective cross-sectional study, the records of 862 patients with MMC who had been treated as inpatients and outpatients at our hospital from 1988 to 2005 were reviewed in our database.

All the patients gave informed consent prior to being included into the study. The study was authorized by the local ethical committee and was performed in accordance with the ethical standards of the 1964 Declaration of Helsinki as revised in 2000 .

MMC patients were usually incorporated into our inpatient and outpatient care after birth, with care continuing past adolescence. We saw these patients at least three times a year. When problems arose that exceeded the capabilities of an outpatient service, our patients were hospitalized. The average time of care for these patients was 15 years [range 4-26 years, standard deviation (SD) 5 years].

Out of 862 patients, 471 were female $(54.6 \%)$ and 391 were male $(45.4 \%)$. During this period, 92 patients $(10.7 \%)$ suffered 170 fractures (Fig. 1). Of these 92 patients, 52 were female $(56.5 \%)$ and 40 were male $(43.5 \%)$. The female patients suffered 99 fractures $(58.2 \%)$ and the male patients suffered 71 fractures $(41.8 \%)$.

Average age at time of fracture occurrence was 10.2 years (range $0-33$ years, SD 7.0 years). Between 8 and 14 years the rate of first fracture occurrence remained high, after which it quickly declined.

Demographic data and the level of paralysis, divided into thoracic, high lumbar (L1-3), low lumbar (L4/5), and sacral, were reviewed. In cases of documented fractures, we also evaluated the X-rays and, if available, the surgery reports. For these patients we recorded their walking ability at the time of fracture, symptoms, fracture site, cause, and treatment.

Ambulation was classified according to Hoffer et al. [19]. In contrast to Hoffer et al. [19], who excluded children under 5 years from their study, we classified all patients using this system.

Surgery or immobilization in a cast was assumed to have triggered the fracture when this had taken place in a period of up to 12 weeks before the fracture occurred.

In $29 \mathrm{MMC}$ patients with various levels of neurological impairment (thoracic, $n=16$; upper lumbar, $n=8$; and lower lumbar, $n=5$ ) and ambulatory status according to Hoffer et al. [19] (community ambulators, $n=3$; household ambulators, $n=7$; nonambulators, $n=19$ ) bone mineral density (BMD) of the femoral neck using dualenergy X-ray absorptiometry (DEXA) was available after fracture occurrence [3].

\section{Statistical methods}

For data entry, we used Microsoft ${ }^{\mathrm{TM}}$ Excel. For statistical analysis we used SAS ${ }^{\mathrm{TM}}$ version 9.1 for Windows.

To analyze the fracture risk with respect to level of paralysis we applied the Cochrane-Armitage trend test and logistic regression. To calculate odds ratios of the fracture risk for ordinal response (level of paralysis) we applied logistic regression. Chi-square test was used to analyze categorical variables. Analysis of variance was used to 


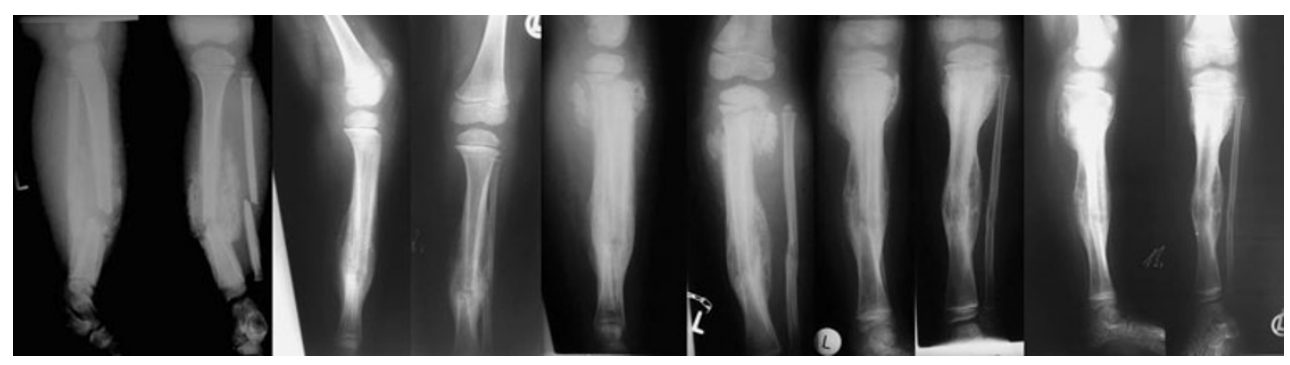

Fig. 1 This 3.5-year-old girl (neurosegmental level of lesion below L3) sustained a fracture of the left lower leg with no history of injury. Bilateral clubfoot surgery with subsequent 10 -week plaster cast immobilization had been performed 11 weeks prior to the fracture.

detect possible differences in bone mineral density (BMD) $z$-scores between level of neurological impairment and ambulatory status. Boxplots were used to visualize the findings. Level of significance $\alpha$ was set to 0.05 .

\section{Results}

Between March 1988 and June 2005, 862 MMC patients were treated at our hospital. During this period, 92 patients (10.7\%) suffered 170 fractures (Fig. 1). The etiology of the fractures is summarized in Table 1 . Out of 92 patients, 56 suffered one fracture, 20 suffered two fractures, and the other 16 patients suffered three or more fractures, 10 fractures being the maximum in the study period. Patients only complained of pain in $8 \%$ of fractures. The most commonly reported symptom was swelling in the area of the fracture $(83 \%)$, followed by local hyperthermia (33\%), fever $(17 \%)$, and redness (14\%).

In $37.9 \%$ of cases the femoral shaft was fractured. Second most often $(34.1 \%)$, the area around the knee joint was affected (supracondylar femur, tibial head, and infracondylar tibia) (Table 2).

Among these 862 patients, the level of paralysis was nearly equally distributed among thoracic $(31.3 \%)$, high lumbar $(28.8 \%)$, and low lumbar $(33.2 \%)$, whereas nearly $60 \%$ of the patients treated for a fracture were paralyzed at the thoracic level (Table 3).

\section{Level of paralysis and fracture risk}

The level of paralysis of the 92 MMC patients who were treated for fractures at our hospital was considerably higher as compared with the 770 patients of our cohort who never sustained any fractures. Thus, thoracic paralysis was found in the fracture group almost twice as often as in the total cohort $(59.8 \%$ vs. $31.3 \%)$. The frequency of low lumbar and sacral paralysis was nearly $40 \%$, whereas only $14 \%$ of the patients who suffered a fracture
The fracture was treated by cast immobilization. Approximately 4 months later, the patient sustained a fracture of the proximal epiphyseal plate of the tibia, again without any history of trauma. The fracture was immobilized in a long leg cast for 7 weeks

Table 1 Fracture etiology

\begin{tabular}{lc}
\hline Etiology of fractures & $\begin{array}{l}\text { Number of fractures, } \\
n(\% \text { of total fractures })\end{array}$ \\
\hline Fall & $59(35)$ \\
Transfer & $28(16)$ \\
Cast immobilization & $62(37)$ \\
Unknown & $21(12)$ \\
Total & $170(100)$ \\
\hline
\end{tabular}

Table 2 Fracture distribution

\begin{tabular}{lc}
\hline Location of fractures & $\begin{array}{l}\text { Number of fractures, } \\
n \text { (\% of total fractures) }\end{array}$ \\
\hline Femur, neck & $5(3)$ \\
Femur, intertrochanteric & $2(1)$ \\
Femur, subtrochanteric & $13(8)$ \\
Femur, shaft & $64(38)$ \\
Femur, supracondylar & $39(23)$ \\
Femur, distal epiphyseal plate & $4(2)$ \\
Tibia, condylar & $5(3)$ \\
Tibia, proximal epiphyseal plate & $1(1)$ \\
Tibia, infracondylar & $9(5)$ \\
Tibia, shaft & $11(6)$ \\
Tibia, supramalleolar & $10(6)$ \\
Tibia, distal epiphyseal plate & $5(3)$ \\
Metatarsal 5 & $1(1)$ \\
Radius, distal & $1(1)$ \\
Total & $170(100)$ \\
\hline
\end{tabular}

demonstrated a low lumbar or sacral level of paralysis. Univariate analysis of risk showed a significant trend (Cochrane-Armitage trend test) towards more fractures with respect to increasing level of paralysis (from sacral $3.5 \%$ to thoracic $17.8 \%$ ). Logistic regression analysis gave similar results. The risk of breaking a bone was sixfold higher for thoracic-level paralysis than for sacral-level paralysis (Table 4). 
Table 3 Distribution of level of lesion in our study population and in patients who sustained a fracture

\begin{tabular}{lcc}
\hline Level of lesion & $\begin{array}{l}\text { All patients } \\
(\%)\end{array}$ & $\begin{array}{l}\text { Patients with } \\
\text { fractures }(\%)\end{array}$ \\
\hline Thoracic & $270(31.3)$ & $55(59.8)$ \\
Upper lumbar (L1-L3) & $248(28.8)$ & $24(26.1)$ \\
Lower lumbar (L4 + L5) & $286(33.2)$ & $12(13.0)$ \\
Sacral & $58(6.7)$ & $1(1.1)$ \\
Total & $862(100)$ & $92(100)$ \\
\hline
\end{tabular}

Table 4 Logistic regression analysis: risk to sustain a fracture at different neurological level of lesion

\begin{tabular}{lcl}
\hline Level of lesion & $\begin{array}{l}\text { Number of fractures } \\
(\%), n=170\end{array}$ & $\begin{array}{l}\text { Odds ratio } \\
{[95 \% \mathrm{CI}]}\end{array}$ \\
\hline Thoracic & $105(61.8)$ & $6.1[1.4 ; 26.0]$ \\
L1-L3 & $45(26.5)$ & $2.9[0.7 ; 12.6]$ \\
L2-L5 & $19(11.2)$ & $2.0[0.5 ; 8.8]$ \\
Sacral & $1(0.6)$ & \\
\hline
\end{tabular}

CI, confidence interval

We also found that, at a thoracic level of paralysis, mainly femur fractures $(81 \%)$ occurred, while at a lumbar level of paralysis, the tibia was more often affected.

Bone mineral density, level of lesion, and ambulatory status

The mean femoral-neck $z$-score was -3.81 (range -3.89 to $-3.69)$ for the patients $(n=16)$ with a thoracic level of lesion, -2.93 (range -2.99 to -2.67 ) for the patients $(n=8)$ with upper lumbar level of neurological impairment, and -2.07 (range -2.23 to -1.9 ) for the patients $(n=5)$ with lower lumbar level of lesion.

Femoral-neck $z$-scores differed significantly $(P<$ $0.0001)$ according to the level of neurological impairment (Fig. 2), with lower $z$-scores in children with a higher level of lesion.

The mean femoral-neck $z$-score was -3.67 (range -3.89 to -2.89 ) for the nonambulators (wheelchair dependent), -2.69 (range -2.95 to -2.10 ) for the household ambulators, and -2.04 (range -2.23 to -1.90 ) for the community ambulators.

Femoral-neck $z$-scores differed significantly $(P<$ 0.0001 ) between nonambulators, household ambulators, and community ambulators (Fig. 3).

\section{Epiphyseal fractures}

A total of nine patients suffered ten epiphyseal fractures (separation). Six patients were female. Average age at time

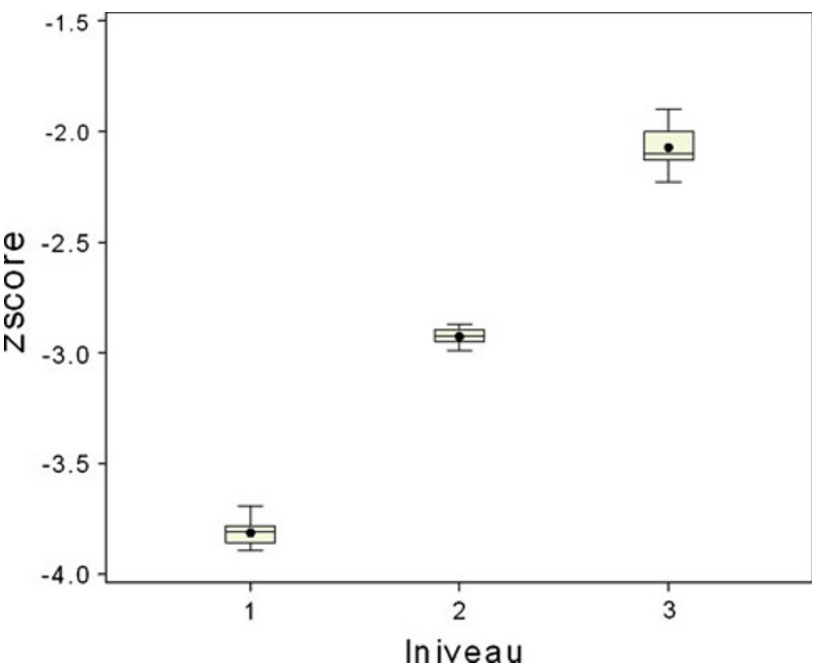

Fig. 2 BMD ( $z$-score) in myelomeningocele patients with different level of neurological impairment. 1 thoracic level. 2 upper lumbar level. 3 lower lumbar level

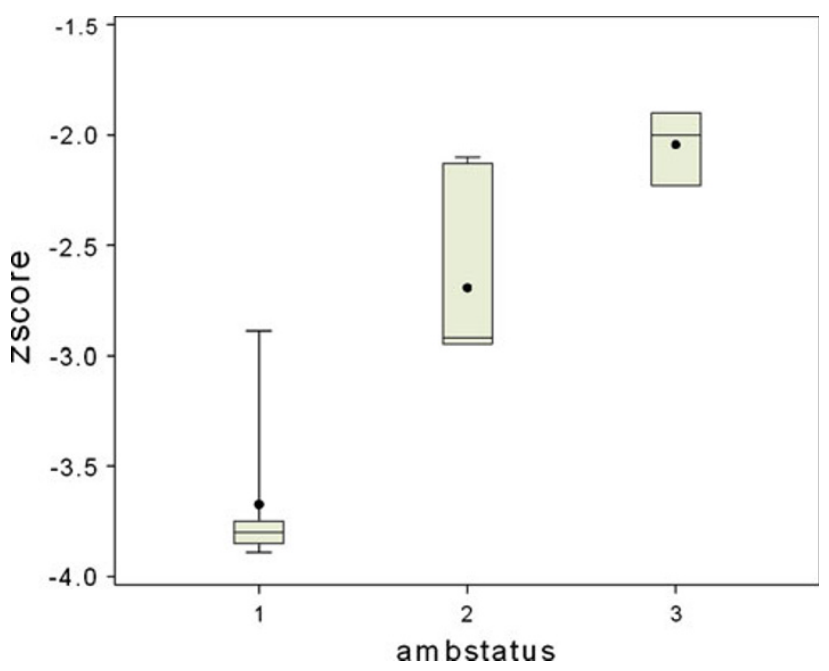

Fig. 3 BMD ( $z$-score) in myelomeningocele patients with different ambulatory abilities. 1 nonambulators. 2 household ambulators. 3 community ambulators

of epiphyseal injury was 8.9 years (range 3.5-15.3 years). At the time of the epiphyseal separation, four patients were between 3 and 4 years of age, and another four patients were between 11 and 13 years of age.

Among the other 83 patients who did not suffer epiphyseal injury, ambulation was only classified as good in $16 \%$ (class 1 according to Hoffer et al. [19]). In contrast, only one single patient who suffered epiphyseal injury could not walk (class 4 according to Hoffer et al. [19]) (Table 5).

Thus, ambulation in patients who suffered epiphyseal injury was significantly better than in the total cohort $(P<0.04)$.

After immobilization in a cast, epiphyseal separations occurred seven times, six of these postoperatively. In one 
Table 5 Comparison of the ambulatory status of patients who had epiphyseal fractures and patients who had other type of fractures

\begin{tabular}{|c|c|c|}
\hline Ambulatory status & $\begin{array}{l}\text { Patients with } \\
\text { epiphyseal plate } \\
\text { fractures, } n(\%)\end{array}$ & $\begin{array}{l}\text { Patients } \\
\text { with other } \\
\text { fractures, } n(\%)\end{array}$ \\
\hline Community ambulators & $5(56)$ & $13(16)$ \\
\hline Household ambulators & $1(11)$ & $9(11)$ \\
\hline $\begin{array}{l}\text { Nonfunctional } \\
\text { ambulators }\end{array}$ & $2(22)$ & $29(35)$ \\
\hline Nonambulators & $1(11)$ & $32(38)$ \\
\hline Total & $9(100)$ & $83(100)$ \\
\hline
\end{tabular}

case, epiphyseal injury occurred with low-impact trauma, and in one case no cause of injury was recorded in the patient's medical history. The total of nine epiphyseal injuries made up 5.3\% of all fractures. Of the other 161 fractures, $55(34.2 \%)$ could be associated with cast immobilization, and therefore damage to the epiphyseal plate was found more often after cast immobilization.

The average duration of cast immobilization associated with subsequent epiphyseal injury was 6.1 weeks (range 4-10 weeks, SD 2 weeks). The mean time before epiphyseal injury occurred after the cast was removed was 2 weeks (range 0-5 weeks, SD 2 weeks).

Patients with epiphyseal injuries were immobilized for 6.6 weeks on average (range 6-9 weeks) to achieve satisfactory healing.

\section{Factors relevant in fractures}

With respect to ambulation in these patients according to the classification of Hoffer et al. [19], a considerable increase in fractures was found in class 3 (nonfunctional ambulators) and class 4 patients (nonambulators).

Of all fractures, $74.1 \%$ were found in class 3 and class 4 patients (Table 6). In contrast, fractures were far rarer in class 1 (community ambulators) and class 2 (household ambulators) patients.

Patients who could not walk well or not walk at all (class 3 and 4) suffered mostly femoral fractures. The proportion of fractures in the tibial area was higher in those patients who could walk moderately well to well (class 1 and 2).

Patients who suffered fractures of the femoral shaft were treated with a femoral brace $(73 \%)$ significantly more often $(P<0.001)$ before fracture occurrence.

For patients who suffered a fracture, the gender distribution was similar: $57 \%(n=52)$ were female and $43 \%(n=40)$ were male. For the probability of suffering a fracture, however, there was no gender-specific preference.
Table 6 Fracture distribution with respect to ambulation according to the classification of Hoffer et al. [19]

\begin{tabular}{llc}
\hline Ambulation & $\begin{array}{l}\text { Number of } \\
\text { patients }(\%)\end{array}$ & $\begin{array}{l}\text { Number of } \\
\text { fractures }(\%)\end{array}$ \\
\hline Class 1 (community ambulators) & $18(19.6)$ & $30(17.7)$ \\
Class 2 (household ambulators) & $10(10.9)$ & $14(8.2)$ \\
Class 3 (nonfunctional ambulators) & $31(33.7)$ & $66(38.8)$ \\
Class 4 (nonambulators) & $33(35.9)$ & $60(35.3)$ \\
Total & $92(100)$ & $170(100)$ \\
\hline
\end{tabular}

Immobilization as cause of fracture

Some $37 \%$ of fractures $(n=62)$ were associated with previous cast immobilization. In our cohort, $26.5 \%$ of fractures $(n=45)$ had received a cast and were immobilized for over 4 weeks. Most of the fractures occurred after a cast immobilization period of more than 4 weeks on average.

Overall, 538 of 862 patients were not immobilized. Out of 538 patients, $58(11 \%)$ were not immobilized prior to fracture occurrence. Out of 862 patients, 253 were immobilized for less than 4 weeks, 10 of whom (4\%) developed a fracture after immobilization. Out of 862 patients, 71 were immobilized for more than 4 weeks, 24 of whom (34\%) developed a fracture after immobilization. Fracture occurrence was significantly higher $(P<0.0001)$ in the patient group immobilized for more than 4 weeks.

\section{Fracture treatment}

A total of 32 patients who suffered a first fracture (34.8\%) were treated operatively with locking plates, and additionally 15 patients $(23.7 \%)$ with a refracture received surgical treatment. None of the 45 patients with operatively treated fractures suffered refracture or multiple fractures. In the group of patients $(n=60)$ with non-operative-treated (cast immobilization) fractures the rate of refractures was very high: $98.3 \%(n=59)$. The 59 patients with refractures were treated in 14 cases operatively and in 45 cases nonoperatively. Fifteen multiple fractures occurred only in the non-operative-treated patient group. Refracture and multiple fracture occurrence was significantly higher $(P<0.0001)$ in the non-operative-treatment group.

\section{Discussion}

In recent years, progress has been made in the areas of surgical and conservative treatment and in our understanding of MMC. A considerable amount of information about the particular aspects of fractures in MMC stems from studies published between the 1960s and 1980s that 
often included only a small number of patients. Utilizing our extensive patient cohort we can re-evaluate older findings and assumptions.

During the study period, 92 patients with MMC suffered one or more fractures, corresponding to a rate of $11 \%$. Older studies have indicated a prevalence of between $9 \%$ and $20 \%[5,9,10,21,23,30,33,34,45]$.

The fracture risk for patients with MMC is sixfold higher in cases of thoracic-level paralysis than in sacrallevel paralysis. The influence of level of paralysis on fracture risk has already been discussed by Lock and Aronson [27], Parsch und Rossak [30], and Dosa et al. [9] with respect to smaller patient groups $(186,120$, and 221 patients). However, the relative risk was not statistically analyzed because of the small numbers and the lack of data for comparison.

In the study conducted by Lock and Aronson [27] high lumbar level of paralysis was found most often, in 15/37 MMC patients who suffered fractures (41\%). In their study, thoracic level of paralysis was reported for 13 of 37 children (35\%), low lumbar for 8 (22\%), and sacral for 1 child (3\%). In spite of the less obvious distribution pattern, they also concluded that fracture prevalence could be directly related to level of paralysis [27].

Parsch and Rossak [30] reported broken legs in 11 of 120 treated children with MMC. Here, too, thoracic level of paralysis was predominant. Seven of $11 \mathrm{MMC}$ children who suffered fractures (64\%) had thoracic, three (28\%) lumbar, and one child (9\%) sacral level of paralysis.

Dosa et al. [9] also considered higher situated level of paralysis as a possible risk factor [9]. Interestingly, however, the mid-lumbar area (L3) was the dominant level of paralysis in their patient cohort $(46.5 \%$ of patients with fractures, 20/43). Another $34.9 \%$ of the patients presented with low lumbar level of paralysis (L4/5). Only 18.6\% demonstrated thoracic/high lumbar level of paralysis (D/L2-3), in contrast to our patients in whom $62 \%$ of all fractures $(105 / 170)$ occurred in those who were paralyzed at the thoracic level.

The differences between patient groups may explain this. In the study by Dosa et al. [9], 49\% of all patients (51\% of the patients who suffered fractures) were between 19 and 58 years old, and $47 \%$ of the patients were ambulatory, i.e., they were considerably older and could walk better than our study patients could.

Our study showed that, with increasingly higher level of paralysis and associated loss of walking ability, the fracture risk increased too. One of the main reasons for a higher prevalence of thoracic-level and high lumbar-level paralysis might be the pronounced osteoporosis that develops in MMC patients due to the lack of vertical load [1, 9, 14, 21, $24,25,29,35,36]$. Our data showed that there is a significant relationship with low BMD in children with MMC who are wheelchair dependent (nonambulators), and those with higher neurological levels. Unfortunately, the DEXA measurement was not performed routinely. Bone mineral density was available in only 29 patients. Because of small sample size, the data should be interpreted critically. It is worthwhile mentioning that the statistical power was very high.

These results are confirmed by the work of Apkon et al. [2].

There have been conflicting results in studies looking at the association of ambulatory status, neurological level of lesion, and bone mineral density [37, 43]. We cannot draw any conclusions concerning the relationship between fracture and reduced BMD because of the study design and missing data.

According to the literature, preventive measures should be carried out in MMC patients so that fractures do not occur: consistent physiotherapy, vertical load [1, 22, 29], concentrating necessary corrective surgery into a few sessions at short intervals [5, 11], and short duration of cast immobilization [30, 42] with early loading. There is no data available concerning appropriate amount of weight bearing and ambulation necessary to maintain or increase bone mineral density in this population.

If there is evidence of vitamin D deficiency and/or poor dietary calcium intake, it would be appropriate to replace such deficits, but routine calcium and vitamin D supplements are not recommended [39]. In children with reduced mobility, there is evidence that increased duration of standing will improve bone density in the spine and femur [39].

In the management of children who have sustained osteoporotic fractures, the treatment for which there is currently most evidence of benefit is bisphosphonates $[39,40]$.

Although there are many different bisphosphonates now available, varying in potency and method of administration, most of the studies undertaken in children have utilised the i.v. preparation pamidronate $[15,17,38,39,44]$, in doses ranging from 2 to $15 \mathrm{mg}$ per $\mathrm{kg}$ per year. For the treatment of our children with MMC with sustained fracture, in a few cases we have followed the recommendations of the published literature. The recommendation that bisphosphonate therapy is suitable to treat osteopenia in MMC is not based on our own study results.

Epiphyseal separations accounted for $6 \%(n=10)$ of the fractures in our patients. In the literature, figures ranging from $4 \%$ to $9 \%$ have been reported $[8,9,27]$. The relatively good walking ability of patients who suffered epiphyseal fractures is in line with observations made by Kumar et al. [24], who reported that epiphyseal fractures occur most often in ambulatory patients with low lumbar paralysis. 
Epiphyseal injuries have a special place among the fractures that occur in patients with MMC, in terms of both etiology and treatment. Mainly patients who can walk well or moderately well (class 1 and 2 according to Hoffer et al. [19]) are affected. If treated conservatively, particularly early and long duration of immobilization are needed to prevent damage to the epiphyseal cartilage, which in turn carries the risk of secondary fractures $[23,30,34]$. Especially for the group of patients who can walk quite well, this represents a high risk that walking ability could worsen.

It was striking in our patients that seven of nine instances $(78 \%)$ of epiphyseal injury were preceded by cast immobilization; for the rest of the fractures this only occurred in 62 fractures $(37 \%)$ in 34 patients. In the pertinent literature this connection was not reported, and although nine epiphyseal injuries are not sufficient to establish a statistically significant relationship, these results should prompt further studies. A popular explanation for epiphyseal injury without low-impact trauma in MMC patients has been that microtraumas occurred repeatedly without a sensory protective mechanism being in place [12, 18, 24, 42].

Epiphyseal separation requires immobilization for between 6 and 9 weeks to achieve satisfactory healing, which is considerably longer than for fractures in which the epiphysis is not involved [24, 31, 35]. Pfeil et al. [31] recommend surgery as a course of action in these cases, because of the inherent danger of epiphyseal nonunion, usually by transcutaneous fixation with Kirschner wires in combination with immobilization. Roberts et al. [35] recommend no loading and stopping physiotherapy for at least 4 weeks. Indeed, Kumar et al. [24] recommend cast immobilization for at least 8 weeks and no loading until $\mathrm{X}$-rays show signs of consolidation.

However, since the risk of secondary fractures increases considerably with immobilization for a longer time period $[1,10,21-23,27,30,31,33,36]$, in addition to surgery, vertical load should be applied early on, depending on $\mathrm{X}$-ray signs of consolidation.

In our patients, cast immobilization over a period of 4 weeks was found to be the cause of fracture in $37 \%$ $(n=62)$ of cases, which is lower than the values of $43 \%$ and $52 \%$ reported in the literature $[30,33]$. These comparatively low rates in our patients might indicate a positive trend as a result of knowledge gained in the past few decades.

Wearing braces represents another possible risk factor in patients who have suffered femoral shaft fractures. Whether this finding reflects more the level of paralysis and degree of walking ability or whether forces acting at the proximal end of the orthotic device promote the fractures cannot be fully explained here.

The possible limitations of our study are: (1) because of the study design (retrospective cross-sectional study) we had no influence on data collection (missing data), and (2) not routinely performed DEXA measurements (selection bias).

It is worthwhile mentioning that this is the first study with such a high number of patients.

Patients with thoracic-level paralysis represent a group of MMC patients with high fracture risk. Postoperative long-term immobilization ( $>4$ weeks) with a cast should be avoided if possible to reduce the risk of secondary fractures. Prevention of fractures in the postoperative period includes starting the child on weight bearing as soon as possible, but carefully, and making every effort to minimize the plaster immobilization time. Once a fracture has occurred, refracture and multiple fracture rates were found only in the nonoperative group treated with plaster immobilization for over 4 weeks.

Based on these results we recommend treating fractures with plaster for not more than 4 weeks. Alternatively, patients with refractures can be treated by surgery, when nonoperative treatment has failed.

Failure to follow this principle may lead to increased osteoporosis, muscle atrophy, and refractures. Considering the peculiar circumstances in fractures in patients with MMC in terms of both diagnosis and treatment, we recommend that these children be treated in outpatient clinics of specialized centers where available and receive routine checkups frequently.

\section{Conflict of interest None.}

Open Access This article is distributed under the terms of the Creative Commons Attribution Noncommercial License which permits any noncommercial use, distribution, and reproduction in any medium, provided the original author(s) and source are credited.

\section{References}

1. Anschuetz RH, Freehafer AA, Shaffer JW, Dixon MS Jr (1984) Severe fracture complications in myelodysplasia. J Pediatr Orthop 4(1):22-24

2. Apkon SD, Fenton L, Coll JR (2009) Bone mineral density in children with myelomeningocele. Dev Med Child Neurol 51(1):63-67

3. Bogunovic L, Doyle SM, Vogiatzi MG (2009) Measurement of bone density in the pediatric population. Curr Opin Pediatr 21(1):77-82

4. Bremer R (2003) Management of spina bifida. Der Orthopade 32(1):85-97 (quiz 97-88)

5. Broughton NS, Menelaus MB (1998) Menelaus` orthopaedic management of spina bifida cystica, 3rd edn. WB Saunders, London Philadelphia Sydney

6. Burney DW Jr, Hamsa WR (1963) Spina Bifida with myelomeningocele. Clin Orthop Relat Res 30:167-174

7. Centers for Disease Control, Prevention. (2008) Use of supplements containing folic acid among women of childbearing ageUnited States, 2007. MMWR 57(1):5-8 
8. Cuxart A, Iborra J, Melendez M, Pages E (1992) Physeal injuries in myelomeningocele patients. Paraplegia 30(11):791-794

9. Dosa NP, Eckrich M, Katz DA, Turk M, Liptak GS (2007) Incidence, prevalence, and characteristics of fractures in children, adolescents, and adults with spina bifida. J Spinal Cord Med 30(Suppl 1):S5-S9

10. Drennan JC, Freehafer AA (1971) Fractures of the lower extremities in paraplegic children. Clinical Orthop Relat Res 77:211-217

11. Drummond DS, Moreau M, Cruess RL (1981) Post-operative neuropathic fractures in patients with myelomeningocele. Dev Med Child Neurol 23(2):147-150

12. Edvardsen P (1972) Physeo-epiphyseal injuries of lower extremities in myelomeningocele. Acta Orthop Scand 43(6): 550-557

13. Eurocat Folic Acid Working Group (2005) Prevention of neural tube defects by periconceptional folic acid supplementation in Europe, vol 2007 http://www.eurocat.ulster.ac.uk/pubdata/ Folic-Acid.html. University of Ulster: Eurocat Central Registry

14. Freeman JM (1974) The practical management of meningomyelocele. University Park Press, Baltimore

15. Glorieux FH, Bishop NJ, Plotkin H, Chabot G, Lanoue G, Travers $\mathrm{R}$ (1998) Cyclic administration of pamidronate in children with severe osteogenesis imperfecta. N Engl J Med 339(14):947-952

16. Golding C (1960) Museum pages. III spina bifida and epiphysial displacement. J Bone Joint Surg 42-B:387-389

17. Grissom LE, Kecskemethy HH, Bachrach SJ, McKay C, Harcke HT (2005) Bone densitometry in pediatric patients treated with pamidronate. Pediatr Radiol 35(5):511-517

18. Gyepes MT, Newbern DH, Neuhauser EB (1965) Metaphyseal and physeal injuries in children with spina bifida and meningomyeloceles. Am J Roentgenol Radium Ther Nucl Med 95:168-177

19. Hoffer MM, Feiwell E, Perry R, Perry J, Bonnett C (1973) Functional ambulation in patients with myelomeningocele. J Bone Joint Surg 55(1):137-148

20. Jacobi G, Preisler B, Kieslich M (1998) Spina bifida: interdisziplinäre Diagnostik, Therapie und Beratung. In: Michael T, von Moers A, Strehl AE, (eds) Berlin New York, De Gruyter

21. James CC (1970) Fractures of the lower limbs in spina bifida cystica: a survey of 44 fractures in 122 children. Dev Med Child Neurol 22(Suppl 22):88

22. Katz JF (1953) Spontaneous fractures in paraplegic children. J Bone Joint Surg 35-A(1):220-226

23. Korhonen BJ (1971) Fractures in myelodysplasia. Clin Orthop Relat Res 79:145-155

24. Kumar SJ, Cowell HR, Townsend P (1984) Physeal, metaphyseal, and diaphyseal injuries of the lower extremities in children with myelomeningocele. J Pediatr Orthop 4(1):25-27

25. Landry M, Fleisch H (1964) The influence of immobilisation on bone formation as evaluated by osseous incorporation of tetracyclines. J Bone Joint Surg 46:764-771

26. Liptak GS, Shurtleff DB, Bloss JW, Baltus-Hebert E, Manitta P (1992) Mobility aids for children with high-level myelomeningocele: parapodium versus wheelchair. Dev Med Child Neurol 34(9):787-796
27. Lock TR, Aronson DD (1989) Fractures in patients who have myelomeningocele. J Bone Joint Surg 71(8):1153-1157

28. Mazur JM, Shurtleff D, Menelaus M, Colliver J (1989) Orthopaedic management of high-level spina bifida. Early walking compared with early use of a wheelchair. J Bone Joint Surg 71(1):56-61

29. Norton PL, Foley JJ (1959) Paraplegia in children. J Bone Joint Surg 41-A:1291-1309

30. Parsch K, Rossak K (1970) Pathological fractures in spina bifida. Archiv fur orthopadische und Unfall-Chirurgie 68(2):165-178

31. Pfeil J, Fromm B, Carstens C, Cotta H (1990) Fractures and epiphyseal injuries in children with myelomeningocele. Z Orthop Ihre Grenzgeb 128(6):551-558

32. Quan A, Adams R, Ekmark E, Baum M (1998) Bone mineral density in children with myelomeningocele. Pediatrics 102(3): E34

33. Quilis AN (1974) Fractures in children with myelomeningocele. Acta Orthop Scand 45:683-897

34. Repasky D, Rickard K, Lindseth R (1976) Ascorbic acid and fractures in children with myelomeningocele. J Am Diet Assoc 69(5):511-513

35. Roberts JA, Bennet GC, MacKenzie JR (1989) Physeal widening in children with myelomeningocele. J Bone Joint Surg 71(1): 30-32

36. Robin GC (1965) Fracture in childhood paraplegia. Paraplegia 3(3): $165-170$

37. Rosenstein BD, Greene WB, Herrington RT, Blum AS (1987) Bone density in myelomeningocele: the effects of ambulatory status and other factors. Dev Med Child Neurol 29(4):486-494

38. Sakkers R, Kok D, Engelbert R, van Dongen A, Jansen M, Pruijs H, Verbout A, Schweitzer D, Uiterwaal C (2004) Skeletal effects and functional outcome with olpadronate in children with osteogenesis imperfecta: a 2-year randomised placebo-controlled study. Lancet 363(9419):1427-1431

39. Shaw NJ (2008) Management of osteoporosis in children. Eur J Endocrinol/Eur Fed Endocr Soc 159(Suppl 1):S33-S39

40. Shaw NJ, Bishop NJ (2005) Bisphosphonate treatment of bone disease. Arch Dis Child 90(5):494-499

41. Soutter FE (1962) Spina bifida and epiphysial displacement. Report of two cases. J Bone Joint Surg 44B:106-109

42. Townsend PF, Cowell HR, Steg NL (1979) Lower extremity fractures simulating infection in myelomeningocele. Clin Orthop Relat Res 144:255-259

43. Valtonen KM, Goksor LA, Jonsson O, Mellstrom D, Alaranta HT, Viikari-Juntura ER (2006) Osteoporosis in adults with meningomyelocele: an unrecognized problem at rehabilitation clinics. Arch Phys Med Rehabil 87(3):376-382

44. Ward L, Tricco AC, Phuong P, Cranney A, Barrowman N, Gaboury I, Rauch F, Tugwell P, Moher D (2007) Bisphosphonate therapy for children and adolescents with secondary osteoporosis. Cochrane Database Syst Rev (Online) 4:CD005324

45. Wenger DR, Jeffcoat BT, Herring JA (1980) The guarded prognosis of physeal injury in paraplegic children. J Bone Joint Surg 62(2):241-246 